\title{
ОДИНОЧЕСТВО И ОСНОВНЫЕ ФЕНОМЕНЫ БЫТИЯ ЧЕЛОВЕКА
}

\author{
T. Р. Рашидова \\ Независимый исследователь
}

Аннотация: Текст доклада автора на Всероссийской научной конференции «Культура между Логосом и Мифом: к проблеме бессознательного (к 80-летию А. Э. Воскобойникова)», которая прошла в Московском гуманитарном университете 26-27 октября 2017 года.

Ключевые слова: бытие; одиночество; философия человека; человек; игра

\section{LONELINESS AND THE PRINCIPAL PHENOMENA OF HUMAN EXISTENCE}

\author{
T. R. Rashidova \\ Independent Researcher
}

Аннотация: The text of the author's speech at the All-Russian Scientific Conference "Culture between Logos and Myth: on the Issue of the Unconscious (dedicated to the 80th anniversary of A. E. Voskoboynikov)", which was held at Moscow University for the Humanities on 26-27 October 2017.

Ключевые слова: existence; loneliness; human philosophy; human; game

Человек обладает определенным личным отношением к миру, т. е. своим личным бытием. Это личное бытие определяется основными феноменами человеческого существования: страхом, смертью, любовью, игрой, коммуникацией, властью. Они формируют Я человека, определяют смысл его жизни. Ими обусловлено все человеческое существование до самых истоков.

Благодаря основным феноменам бытия индивид постигает себя в различных образах (смертного, любящего, играющего и т. д.) и посредством этого пытается истолковать существование всего, что его окружает. Феномены бытия взаимосвязаны и взаимозависимы, они, можно сказать, переплетены между собой. Для нас особый интерес представляет воздействие данных феноменов на одиночество и его связь с ними. Смысл одиночества может быть выявлен лишь в его взаимосвязях с другими феноменами бытия человека. 
Игра. Игры и развлечения помогают человечеству отвлечься от уединенных размышлений, проблем овладевающих человеком, оставшимся наедине со своим «Я».

Согласно Паскалю, к числу игр могут быть причислены не только развлечения, но также и выполнение должностных обязанностей и даже войны. Человек старается погрузиться в дела, занять служебный пост, приносящий множество хлопот, занимающий все его время, с одной целью - не остаться наедине с собой.

Одной из важных (для раскрытия нашей темы) особенностей игры является характер противостояния. Игры «в одиночку» не бывает. В игре обязательно присутствие некоего «другого», того с кем играют и кто откликается встречным ходом на ход играющего. Игре присуща двойственная реальность, в процессе игры игрушки как будто обретают самостоятельную подлинную жизнь.

Очень интересно переплетение одиночества, игры и коммуникации. Игровая грань - крайне интересное проявление коммуникации. Игра способствует созданию атмосферы легкости и, в то же время, двойственности, как коммуникации, так и значения, которое ей придается. Все это в определенной степени раздвигает границы коммуникации, границы восприятия мира, делает его более радостным. Однако, в связи с тем, что игра это «не по-настоящему», воздушность, создаваемая ею, чаще всего оборачивается неосновательностью. В подобной неустойчивой ситуации очень легко утратить ориентиры. Окружающий мир выглядит недостоверным, непостоянным и полным опасностей. В конечном итоге играемая роль, отчуждается от человека, превращая его в управляемую куклу и порождая ощущение внутренней опустошенности и одиночества.

Человек может настолько увлечься игрой, что она сама станет нестерпимой. Игра интересна, радостна, она избавляет нас от привычной обыденности жизни и, тем не менее, игра не должна переходить границы игрового пространства.

Интересна в этом отношении коммуникация в виртуальном пространстве. Зачастую люди, проводящие много времени в сети на различных чатах, коммуникационных порталах берут псевдонимы (ники). Это дает возможность более многогранного, пусть даже и иллюзорного, игрового самоосуществления и причем (что, немало важно) совершенно анонимно. В результате человек получает большую свободу, чем та, которая обычно дана ему: он может наблюдать за другими, скрывшись от них за своим псевдонимом.

Подобная игра приводит человека к новому восприятию самого себя. Происходит своего рода разделение на настоящее Я и другое, играющее, неподлинное Я, скрытое под маской. Играя под псевдонимом, человек стре- 
Научные труды Московского гуманитарного университета 2018 № 3

мится реализовать (пусть даже в игровой, виртуальной жизни) свой, не имеющий возможность проявиться иначе, воображаемый портрет. Обретая игровое Я, человек, с одной стороны, заряжается новыми эмоциями и переживаниями, он вступает в виртуальную коммуникацию. С другой стороны, он обладает также своим истинным Я, которое продолжает жить в обыденном пространстве действительности. Это может привести к внутреннему кризису. Игровое Я, становится чуждым, по отношению к истинному Я. Эта чуждость игрового Я может привести к одиночеству, отчуждению от подлинной жизни, заставить сомневаться в ее обоснованности. Человек может оказаться в ситуации раздвоенности между подлинным существованием и игровым, в результате нарушается стабильность и безопасность его жизненного мира.

Любовь. За многими событиями жизни окружающих нас людей мы наблюдаем, как бы издали, сквозь границу равнодушия, безучастно. Как безразличные очевидцы мы можем вдруг стать свидетелями несчастного случая, смерти. В человеческом сосуществовании, в принципе, доминирует безразличие, «непринятие во внимание». Это вполне объяснимо тем фактом, что поддерживать контакт и эмоционально наполненные связи со всеми окружающими нас людьми абсолютно невозможно. К тому, же истинно позитивное сосуществование отвечает требованиям избирательности. Каждый человек, находящий отклик в нашем сердце выделяется нами из множества чужих, «не принимаемых во внимание» людей. В связи с этим, любовь можно определить как подтверждение существования другого человека. «...Быть любимым - это значит быть самым существующим из всего и всех» (Рубинштейн, 2002: 369).

Истинная любовь утверждает существование одного человека для другого не в качестве средства (носителя определенной функции), а в качестве цели. В тоже время, любовь подтверждает существование не только любимого, но и самого любящего. Ведь пребывая в состоянии любви, человек становится способным постичь всю полноту бытия. Любовь не просто содействует личностному развитию человека, она позволяет обрести качественно новое восприятие действительности, более осознанное и более содержательное. Подлинное глубокое, а не поверхностное знание жизни открывается человеку только посредством любви.

В полной мере это выражается в диалектических отношениях Я и Ты, раскрывающих родовую природу человека. Любовь, подтверждающая существование вне границ личного «Я» и отвергающая, тем самым, солипсизм, должна быть смыслом жизни каждого индивида.

Согласно Фрейду, любовь, в первую очередь сексуальная, является основой человеческой культуры. Эрос «инстинкт жизни» объединяет в еди- 
ное целое все человечество: семьи, племена, народы, нации. Либидо связывает людей гораздо прочнее, чем потребность в совместном труде.

Возможно, именно поэтому человек очень часто стремится к любви с целью преодолеть свое одиночество, отделенность. В связи с этим, противоположностью любви является не только ненависть, которая отказывает другому человеку в существенности его бытия. В большей степени от любви отличаются всевозможные формы псевдолюбви, порожденные стремлением человека избежать свое одиночества. Разобщенность, характерная современному обществу, привела к тому, что любовь воспринимается в качестве некоего сентиментального чувства, игры фантазии или же болезненной привязанности. В то время как она не только основное свойство и способность человеческой натуры, но и фундаментальный закон человеческого бытия. Любовь - это стремление побороть деструктивное влияние окружающей среды, проявляющееся в возрастающем ожесточении, стандартизации мышления и поведения.

Псевдолюбовь - всего лишь иллюзия, создаваемая человеком, стремящимся укрыться в ней от своих тревог и страхов. Результатом становится поверхностное и мнимое сплочение, после которого отчужденность между двумя людьми возрастает в большей степени. В подобных союзах один из партнеров зачастую отказывает себе в праве на индивидуальную, независимую от «любимого» жизнь. Все свои мысли он сосредоточивают на нем и вокруг него. Так складываются симбиотические отношения, в которых каждый из членов утрачивает свою индивидуальность. Один человек, отказываясь от своей индивидуальности ради другого, лишает и его этого существенного качества.

Истинная любовь имеет мало общего с подобного рода привязанностью. Ведь любовь есть акт свободного выбора, она не должна превращаться в необходимость. Любовь - это скорее встреча двух независимых индивидуальностей, выбравших совместную жизнь. Подлинно любить возможно только в том случае, если сам человек представляет собой сформировавшуюся, зрелую личность. И в этом проявляется другая, позитивная связь любви и одиночества. Ведь оно позволяет человеку открыть самого себя, узнать, что значит быть самим собой. Если взаимные отношения лишают возможности выбора, ограничивают внутреннюю свободу, любовь превращается в необходимость. Настоящая любовь не лишает человека его независимой сущности. Как раз наоборот, истинно любящий оберегает отдельность и уникальную индивидуальность любимого. «Существует только одно чувство, удовлетворяющее человеческую потребность в единении с миром и вместе с тем дающее ему ощущение целостности и индивидуальности, - любовь. Любовь - это объединение с кем-либо или чем-либо вне самого себя при 
Научные труды Московского гуманитарного университета 2018 № 3

условии сохранения обособленности и целостности своего собственного Я» (Фромм, 2006: 125). Отсутствие способности воспринимать существование другого человека как отличное, отдельное от своего собственного является нарциссизмом.

Отдельность партнеров укрепляет и обогащает их единение. Любовь парадоксальна - люди видят в ней свое спасение от одиночества, однако истинный союз не может быть создан индивидами, боящимися одиночества. В связи с этим будет уместно привести отрывок из эссе Дж. Халиля: «пусть близость ваша не будет чрезмерной, и пусть ветры небесные пляшут меж вами. Наполняйте чаши друг другу, но не пейте из одной чаши. Давайте друг другу вкусить своего хлеба, но не ешьте от одного куска. Пойте, пляшите вместе и наслаждайтесь, но пусть каждый из вас будет одинок, как одиноки струны лютни, хотя от них исходит одна музыка. Стойте вместе, но не слишком близко друг к другу. Ибо колонны храма стоят порознь, и дуб и кипарис не растут рядом» (Джебран Халиль, Электр. ресурс).

Власть. Бытие человека разворачивается на стыке двух миров: внешнего (окружающего) и внутреннего (душевного). Его внешний и внутренний миры подвержены взаимному влиянию друг на друга. Ведь постижение самого себя происходит для человека в результате его практической деятельности. Ему свойственно стремление творить себя из того, что является непосредственно данным и существует как нечто внешнее. Таким образом, человек меняет окружающий мир, объекты и, тем самым, находит в них свои собственные определения. Посредством трансформации внешнего мира человек не только изменяет себя, но и воплощает в окружающей действительности. Тем самым, человек в результате обретения власти самоутверждается. Власть выступает способом подтверждения значимости и реальности личного бытия, как один из возможных вариантов самореализации. Человек преодолевает свою отчужденность, достигает единства с окружающей его действительностью, путем ее постижения и обретения власти над ней. Иными словами, он является смысловым центром объединения самого себя и реального мира.

В качестве субъекта власти может выступать и общество, в котором находится человек. Переломным пунктом истории человечества стало отделение человека от природы и противопоставление ей. В результате чего, изначальная неделимость природы распалась на субъект и объект. Тем не менее, уровень освобождения от природы возмещается более значительным подчинением индивида обществу.

Общество вынуждает личность приспосабливаться к его законам. Подобное приспособление человека к социальным нормам продолжается в течение всей его жизни. Это определяется тем, что удовлетворение потреб- 
ности установить единство с другими людьми - важнейшее условие достижения психического здоровья человека. Человек, спасаясь от разобщенности и одиночества, стремится раствориться (передать себя во власть) в каком-нибудь большом групповом образовании, подчиняясь императивам, действующим в нем. Вследствие этого он устраняет обособленность своего индивидуального существования, ощущая себя принадлежным к кому-то или чему-то более значимому. Однако подобное растворение не несет в себе объединения личности с личностью, Как раз наоборот, оно приводит человека к лишению личной индивидуальности, снижает его возможности. Ликвидирует из бытия индивидов подлинные экзистенциальные ценности, путем признания тривиальных шаблонов жизни в качестве единственного и абсолютно естественного способа бытия.

Обратной стороной данного способа избежать одиночества является власть над другими. Человек может обрести единство с окружающим миром, используя власть над ним. Притягательность власти объясняется тем, что принадлежность человеку других людей, позволяет ему выйти за границы своего личного существования.

Таким образом, отсутствие эмоционально насыщенных и глубоких связей в совокупности с суждением об окружающем мире как безучастном и враждебном побуждает личность самой стать источником власти, или же подчиниться тому, кто облечен властью. Однако ни стремление к подчинению (мазохистская тенденция) ни стремления к господству (садистская тенденция) не способны дать человеку чувство идентичности и единства. А. Э. Воскобойников очень четко охарактеризовал это: « Когда рвутся связи между людьми и воцаряется некоммуникабельность? Это происходит тогда, когда другой человек вместо цели превращается в средство и из страдающего и переживающего подобно тебе субъекта начинает восприниматься как вещь. А с вещью диалог невозможен» (Воскобойников, 2012: 122; курсив источника).

В свете проблемы одиночества феномен власти тесно переплетается с феноменом любви. Без любви другой человек может принадлежать своему господину лишь как функция. Как личность человек принадлежит человеку, в том случае, когда он добровольно передает во власть не функциональный предмет, но себя. Власть, в данном случае, трансформирует взаимоотношения между людьми таким образом, что индивидуальное «Я» человеческой личности начинает рассматриваться только как объективное «Я», определяемое своими функциями. Тем самым, человек перестает существовать для другого, как личность, а определяется в качестве предмета.

смерть и страх. Особо остро переживается одиночество в «пограничных ситуациях». Одна из них - обостренное переживание своей смерт- 
Научные труды Московского гуманитарного университета 2018 № 3

ности или ее угрозы ближним. Событие смерти влечет за собой ситуацию разрыва, расставания, одиночества. Смерть «другого» - мое одиночество. Смерть ближнего включает меня в свою структуру, поскольку сопровождается сильным и глубоким переживанием. Разлука, следующая за смертью, убивает и нас. Мы уходим из жизни «другого» (умершего). «Смерть другого - это моя фатальная жизненная неудача, ускользнувшая возможность личного ис-полнения» (Тищенко, 2009: 701).

Смерть воспринимается человеком как неведомая, повергающая в трепет бездна, неминуемо сталкивающая его с самим собой, со всей его судьбой, порождающая раздумья и нарушающие покой вопросы. Л. Н. Толстой полагал, что главная причина, по которой человек боится смерти, заключается не в завершении жизни, а в обнажении ложности проживаемой им жизни. «Люди, боящиеся смерти, боятся ее оттого, что она представляется им пустотою и мраком; но пустоту и мрак они видят потому, что не видят жизни» (Толстой, 1984: 97).

Чувство трагического одиночества, порождающего гнетущую безысходность и тоску, с философской и художественной глубиной воссоздано в произведениях Сартра, Камю, Кафки и др. «Она знала, что нужна Марселю... ощущая, что он не хочет быть одиноким, не хочет стареть и умирать, и упрямое выражение, которое появлялось тогда у Марселя, она порою узнавала на лицах других мужчин - единственное, в чем были похожи эти сумасшедшие, скрывавшие свое безумие под маской разума, пока оно не одолевало их и не швыряло в отчаянном порыве к женщине, даже без вожделения, лишь бы укрыться в ее объятиях от одиночества и мрака, которого они так страшатся» (Камю, 1990: 461).

Смерть, приходящая к человеку в силу природной закономерности, переживается им только в одиночку, как индивидуальная трагедия. Вследствие этого, смерть раскрывает перед человеком возможность понять глубину и значимость жизни.

Таким образом, смерть придает смысл человеческой жизни. Пожалуй, лучше всего это описано в повести Л. Н. Толстого «Смерть Ивана Ильича». На смертном одре, пребывая в состоянии «страшного одиночества», «среди многолюдного города и своих многочисленных знакомых и семьи, одиночества, полнее которого не могло быть нигде: ни на дне моря, ни в земле» (Толстой, 1982: 102) герой осознает всю тщетность проведенной им жизни. «Как мучения все идут хуже и хуже, так и вся жизнь шла все хуже и хуже», - думал он. Одна точка светлая там, назади, в начале жизни, а потом все чернее и чернее» (там же).

Однако не всегда приближение смерти влечет за собой одиночество, гораздо хуже, когда происходит обратное. Порой одиночество становится 
причиной смерти. Страх перед одиноким существованием, внутренней пустотой, бессмысленностью жизни настолько сильно овладевает человеком, что даже смерть кажется ему меньшим злом. В данном случае речь идет не только о добровольной физической смерти (самоубийстве), но об общей тенденции некрофильского образа жизни, стремлении к деструктивности, являющимися последствиями влечения к смерти - Танатосу. Человек, осознающий, факт своего «несуществования» перед лицом других людей, решает не существовать и для себя. Его подлинным стремлением становится «существование к смерти».

Вопрос деструктивных тенденций получил свое освещение в работах Э. Фромма, посвященных анализу массового распространения социальных действий некрофильских личностей, социальных черт садизма и мазохизма.

В состоянии, когда одинокий человек не способен установить единство с самим собой, с природным и социальным миром вокруг себя, он выбирает другую альтернативу: идет по пути разрушения. Это вызвано стремлением, во что бы то ни стало, привлечь внимание к своей персоне, заставить мир говорить о себе и вырваться из рамок забвения, в которые он был загнан. В данном случае возможность актуализации личностного начала выражается в агрессии. Агрессия выражает озлобленность к внешнему миру, безучастному к личной судьбе одиночки. «Другой» воспринимается как враг, который причиняет страдание своим равнодушием и поглощенностью личными проблемами, усиливает чувство одиночества и неполноценности, не позволяя разрушить границы безучастия. Статистика показывает, что большинство покушений на жизнь знаменитостей, акты вандализма совершаются одинокими, заурядными индивидами. Они стремятся отомстить за свою ущербность внешне успешному обществу, внушая людям страх, заставляя их страдать. «Разрушить мир - это последняя, отчаянная попытка не дать этому миру разрушить меня» (Фромм, 1994: 194). Каждый человек должен расти, выразить себя, наиболее полно прожить свою жизнь. Если влечение к жизни сдерживается, проявляется влечение к смерти, разрушительным действиям.

Трагизм данной ситуации заключается также и в следующем. Независимо от того, какого эффекта достигает проявление деструктивности, любое разрушение, направленное вовне, разрушает и сам источник своего распространения. Жажда разрушать, агрессия нравственно убивают человека, отделяют от других людей, подчиняют его своему губительному влиянию.

Коммуникация (общение). Несмотря на то, что существование «Я» может показаться полностью автономным, оно по самой сути своей диалогично, то есть немыслимо вне общения, вне коммуникации. Индивидуальная и социальная составляющие в совокупности представляют собой ядро лич- 
Научные труды Московского гуманитарного университета 2018 № 3

ности. Человек как личность не только раскрывается, но и порождается в процессе общения.

Общение с другими помогает человеку в общении с самим собой, другими словами, готовит его к одиночеству. С другой стороны, пребывая в одиночестве, человек получает возможность лучше понять себя и других, он становится более восприимчивым к познанию природы межличностных взаимоотношений.

Осознание своей отдельности и одиночества есть неотъемлемая часть смысла жизненного опыта, поскольку именно одиночество помогает осознать ценность общения и жизни в человеческом обществе. Благодаря одиночеству «Мы» может стать плодотворным союзом двух индивидуальностей. Только в одиночестве мы можем понять свое ценность существования своего «Я». Однако каждый человек открывает себя, свое «Я» через «Другого», в результате общения с другими, благодаря этому формируется «Мы».

Иногда необходимость «Другого» воспринимается как узость личности, отсутствие самодостаточности. В то время как, на самом деле, она есть доказательство коммуникабельности человека, подтверждение открытости его бытия, наличие интереса к жизни, новому. «Другой» может помочь в открытии качественно иного жизненного пространства, в котором реализуются неведанные раннее, скрытые стороны «Я». Таким образом, впадая в крайность своей самодостаточности, человек не столько обманывается, сколько губит самого себя. Излишняя самодостаточность может обернуться пропастью, проложенной человеком самому себе в своем бытии.

Преувеличение степени своей уникальности, непохожести на других может явиться причиной замкнутости, страха показаться смешным. Боязнь утратить в общении свою неповторимую личность влечет за собой острую неудовлетворенность существующими формами общения и, в тоже время, активизирует жизненно необходимую потребность открыть душу.

На современного человека ежедневно обрушиваются не только новые информационные потоки. Но и постоянное и подчас вынужденное общение, лишенное порой разумных пределов и духовного содержания

Стоит ли считать безграничное общение, интенсивно поглощающее всю внутреннюю духовную жизнь человека единственной альтернативой одиночеству? Ведь если под общением подразумевается лишь обмен информацией, не сопровождающийся ее интимным для человека смысловым значением, то такое псевдообщение ни в какой степени не противостоит одиночеству и даже совсем наоборот - порождает его. Ведь то общение, при котором теряется естественная ограниченность, индивидуальность, глубина, эмоциональная окрашенность, легко превращается в тирана личности. Очень часто случается так, что «Другой» остается за гранью диалога, 
делая недостижимым приближение к единому существованию.

Путь к подлинно человеческому сосуществованию лежит не через безучастный обмен информацией. Оно достигается в результате такого общения, которое затрагивает потаенные глубины человеческой личности, позволяет постичь «Я» другого человека в его уникальности, в неповторимой жизненной ситуации. В философии К. Ясперса данный вид общения обозначен как экзистенциальная коммуникация.

Именно экзистенциальная коммуникация позволяет одному человеку понять и услышать «Я» другого. Таким образом, в результате глубинно-личностного общения происходит раскрытие двух подлинных имманентных экзистенций. При этом каждый участник экзистенциальной коммуникации (при условии абсолютной открытости перед «Другим») обретает возможность встретить и узнать свою личную сущность за пределами себя самого, то есть обрести себя в другом человеке

Экзистенциальная коммуникация способна разрушить «предметное», «вещное» восприятие другого. Ведь взаимное сопереживание и признание значимости другой личности не только за внешние достоинства (красота, ум, социальный статус), но и за нечто скрытое, заключенное в глубине человеческого существа, в корне истребляют эту чисто предметную установку. Свое подлинное «Я» человек обретает в подлинном диалоге с «Ты». Подлинный диалог отличается от дискуссии, в которой каждый говорящий стремится к самоутверждению за счет своего собеседника, он представляет собой общение личности с личностью. Основанием для осуществления данного вида диалога является осознание и признание инакости «Другого», его отличия от «Я». Непохожесть «Другого», иной собственный взгляд на мир открывают для «Я» новые горизонты постижения окружающей реальности.

Таким образом, можно сделать следующее заключение. Подлинное общение (экзистенциальная коммуникация, настоящий диалог) возможно в том случае, когда замкнутость и отстранение от совместного существования уступают место соприкосновению и взаимной открытости экзистенций.

Завершая анализ взаимосвязи одиночества и основных феноменов бытия человека, можно сделать следующий вывод. Одиночество остраняет всю полноту конкретности человеческого бытия. Переплетаясь с феноменами бытия, одиночество открывает индивиду видение их подлинного внутреннего содержания, в результате чего человек не просто отражает бытие, но и порождает его в индивидуально-личностных формах. Именно одиночество заставляет человека искать истинный ответ на проблему его личного существования, становясь критерием подлинности человеческого бытия. 


\section{СПИСОК ЛИТЕРАТУРЫ}

Воскобойников, А. Э. (2012) Бессознательное и сознательное в уединении и на миру // Знание. Понимание. Умение. №2. С.119-125.

Джебран Халиль Пророк [Электронный ресурс] // URL : http://lib.ru/ POEEAST/prophet.txt (дата обращения: 27.04.2012).

Камю, А. (1990) Избранное. М. : Правда.

Рубинштейн, С. Л. (2002) Бытие и сознание. Человек и мир. СПб. : Питер.

Тищенко, П. Д. (2009) Смерть, могильник и человеческое «Я» // Человек-наука-гуманизм : к 80-летию со дня рождения академика И. Т. Фролова. М. : Наука.

Толстой, Л. Н. (1982) Смерть Ивана Ильича // Толстой, Л. Н. Собр. соч. : в 22 т. М. : Художественная литература. Т. 12.

Толстой, Л. Н. (1984) О жизни // Толстой, Л. Н. Собр. соч. : в 22 т. М. : Художественная литература. Т. 17.

Фромм, Э. (1994) Иметь или быть. М. : Прогресс.

Фромм, Э. (2006) Здоровое общество М. : АСТ.

Дата поступления: 30.12.2017 г.

Рашидова Тамила Ризвановна - кандидат философских наук, независимый исследователь. Эл. адрес: tamila24@list.ru

Rashidova Tamila Rizvanovna, Candidate of Philosophy, Independent Researcher. E-mail: tamila24@list.ru

\section{Для цитирования:}

Рашидова Т. Р. Одиночество и основные феномены бытия человека [Электронный ресурс] // Научные труды Московского гуманитарного университета. 2018. № 3. URL: http://journals.mosgu.ru/trudy/article/view/744 (дата обращения: дд.мм.гг.). DOI: 10.17805/trudy.2018.3.7 